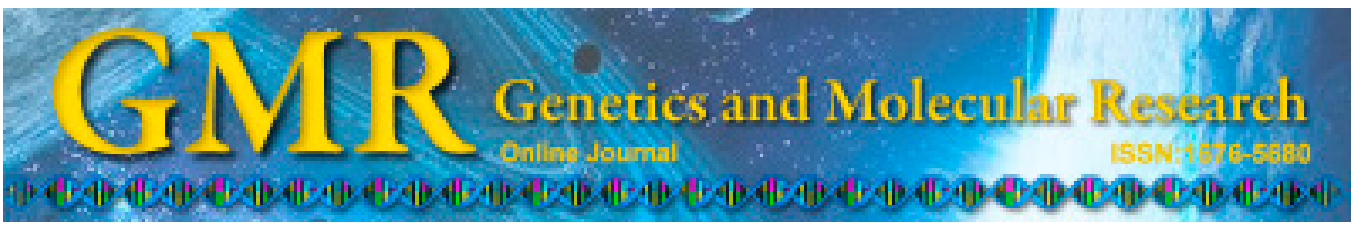

\title{
Osteoprotegerin polymorphisms in Chinese Han patients with rheumatoid arthritis
}

\author{
X.H. Ye ${ }^{1}$, J.L. Cheng ${ }^{1,2}$ and R.P. Liu ${ }^{3}$ \\ ${ }^{1}$ Department of Endocrinology, Affiliated Hospital of Nanjing Medical University, \\ Changzhou Second People's Hospital, Changzhou, Jiangsu, China \\ ${ }^{2}$ Institute of Diabetes Research, Affiliated Hospital of Nanjing Medical University, \\ Changzhou Second People's Hospital, Changzhou, Jiangsu, China \\ ${ }^{3}$ Department of Orthopedics, Affiliated Hospital of Nanjing Medical University, \\ Changzhou Second People's Hospital, Changzhou, Jiangsu, China \\ Corresponding author: R.P. Liu \\ E-mail: 1rp216@sina.com
}

Genet. Mol. Res. 14 (2): 6569-6577 (2015)

Received October 22, 2014

Accepted February 10, 2015

Published June 12, 2015

DOI http://dx.doi.org/10.4238/2015.June.12.11

ABSTRACT. In order to investigate the association between
osteoprotegerin (OPG) gene polymorphisms and rheumatoid
arthritis (RA), we studied OPG rs $3102735 \mathrm{~T} / \mathrm{C}$ and rs $2073618 \mathrm{G} / \mathrm{C}$
polymorphisms in a Chinese Han population comprising 574 patients
with RA and 804 controls. Genotyping by matrix-assisted laser
desorption/ionization time-of-flight mass spectrometry (MALDI-TOF
MS) was conducted. Our data indicated that OPG rs3102735 T/C and
rs $2073618 \mathrm{G} / \mathrm{C}$ polymorphisms were not associated with the risk of
RA. However, among older patients $(\geq 55$ years), patients with the OPG
rs $3102735 \mathrm{TC}(\mathrm{TC} v s \mathrm{TT}$ : OR $=0.68,95 \% \mathrm{CI}=0.49-0.96, \mathrm{P}=0.029)$
and TC/CC $(\mathrm{TC}+\mathrm{CC} v s \mathrm{TT}$ : OR $=0.69,95 \% \mathrm{CI}=0.49-0.96, \mathrm{P}=0.026)$
genotypes showed a significantly lower risk of RA than patients with
the TT genotype, while patients with the OPG rs $2073618 \mathrm{GC}(\mathrm{GC} v s$
GG: OR $=1.53,95 \% \mathrm{CI}=1.13-2.07, \mathrm{P}=0.006)$ and $\mathrm{GC} / \mathrm{CC}(\mathrm{GC}+\mathrm{CC}$
vs GG: OR $=1.43,95 \% \mathrm{CI}=1.07-1.92, \mathrm{P}=0.015)$ genotypes showed a
significantly higher risk of RA than patients with the GG genotype. We 
also found a significantly increased risk of RA associated with the OPG rs2073618 GC (GC vs GG: $\mathrm{OR}=1.44,95 \% \mathrm{CI}=1.07-1.93, \mathrm{P}=0.018)$ and $\mathrm{GC} / \mathrm{CC}(\mathrm{GC}+\mathrm{CC} v s \mathrm{GG}: \mathrm{OR}=1.39,95 \% \mathrm{CI}=1.04-1.86, \mathrm{P}=0.024)$ genotypes among functional class III+IV patients. Our results were obtained from only a moderate-sized sample and, thus, a larger study with a more diverse ethnic population is needed to confirm these results.

Key words: Osteoprotegerin; Polymorphisms; Rheumatoid arthritis; Molecular epidemiology

\section{ITRODUCTION}

Rheumatoid arthritis (RA) is a systemic autoimmune disease characterized by inflammation of the synovial membrane, which may result in structural damage to the cartilage and bone. The pathogenesis of RA is poorly understood, but is thought to be multifactorial, involving multiple genes and environmental triggers (Kalinina Ayuso et al., 2014). Osteoclast formation and activation at the cartilage-pannus junction make the greatest contribution to the destruction of bone matrix in patients with RA (Gravallese et al., 2000; Takayanagi et al., 2000; Haynes et al., 2001). Bone loss in RA includes joint erosion, peri-articular bone loss, and osteoporosis. Several studies have suggested that many inflammatory cytokines found in RA synovial tissue promote osteoclast formation and bone resorption (Chu et al., 1992; Deleuran et al., 1992). Additionally, recent evidence indicates that osteoprotegerin (OPG) plays an important role in osteoclastogenesis (Yasuda et al., 1998; Takayanagi et al., 2000; Haynes et al., 2001).

The receptor activator of the nuclear factor- $\mathrm{KB}$ ligand (RANKL)/RANK/OPG pathway plays an important role in the regulation of bone remodeling, osteoclast differentiation, and osteolysis (Baud'huin et al., 2007). OPG, a decoy receptor for RANKL, inhibits osteoclast differentiation and function, and bone resorption in the RANKL/RANK/OPG system, by preventing the interaction of RANKL with its receptor RANK (Kondo et al., 2004). Additionally, the gene encoding OPG influences the development of osteoporosis (Wittrant et al., 2004; Boyce and Xing, 2008).

The OPG gene is located on chromosome 8q24.2. The promoter region of the human OPG gene includes various binding sites that may mediate the expression of the OPG gene via different calciotropic factors (Morinaga et al., 1998; Hofbauer and Heufelder, 2001). Previous studies have suggested that the polymorphisms in the promoter and untranslated regions of this gene contribute to the genetic regulation of joint destruction in RA (Knevel et al., 2014; Yoshida et al., 2014). However, other conflicting studies have suggested that these polymorphisms, such as rs $3102735 \mathrm{~T} / \mathrm{C}$ and rs $2073618 \mathrm{G} / \mathrm{C}$, may not be relevant in this role. Furuya et al. (2007) revealed that the OPG gene polymorphism rs2073618 was not associated with the amount of joint destruction in early RA in Japanese patients. Two studies from Germany and China also indicated that OPG rs $3102735 \mathrm{~T} / \mathrm{C}$ and $\mathrm{rs} 2073618 \mathrm{G} / \mathrm{C}$ polymorphisms were not related to RA (Assmann et al., 2010; Xu et al., 2014). Hence, we hypothesized that the OPG rs3102735 T/C and rs2073618 G/C polymorphisms were not associated with RA.

The aim of this study was to investigate the possible relationship between OPG gene polymorphisms and susceptibility to RA, and more importantly to determine whether single nucleotide polymorphisms (SNPs) of the OPG gene played a role in bone and joint destruction in RA. To this end, we performed OPG gene genotyping in a hospital-based case-control study in a Chinese cohort of 574 patients with RA and 804 controls. 


\section{PATIENTS AND METHODS}

\section{Study subjects}

The study protocol was approved by the Nanjing Medical University Ethics Committee (Nanjing, China), and all patients provided written informed consent.

In total, 574 patients with RA who fulfilled the RA of the American College of Rheumatology 1987 classification criteria (Silman, 1988) were consecutively recruited from the Changzhou Second Hospital-Affiliated Hospital of Nanjing Medical University (Changzhou, China), the Changzhou First Hospital (Changzhou, China), and the Changzhou Traditional Chinese Medical Hospital (Changzhou, China), between September 2010 and September 2013. The controls were patients without RA, matched for age ( \pm 5 years) and gender, and recruited from the same institutions during the same period. Most of the controls were trauma patients.

Each patient was interviewed by trained personnel using a pre-tested questionnaire to obtain information on demographics and the risk factors related to RA. After the interview, 2 $\mathrm{mL}$ peripheral blood was collected from each patient.

\section{Isolation of DNA and genotyping by matrix-assisted laser desorption/ionization time-of-flight mass spectrometry (MALDI-TOF MS)}

Blood samples were collected using Vacutainers (Becton Dickinson, Franklin Lakes, NJ, USA) and transferred to test tubes containing ethylenediaminetetraacetic acid (EDTA) (Dazhi, Nanjing, China). Genomic DNA was isolated from whole blood using the QIAamp DNA Blood Mini Kit (Qiagen, Hilden, Germany). Genotyping was performed by MALDITOF MS using the MassARRAY system (Sequenom, San Diego, CA, USA), as described previously (Cheng et al., 2012).

\section{Statistical analyses}

Differences in demographics, variables, and genotypes of the OPG rs3102735 T/C and rs $2073618 \mathrm{G} / \mathrm{C}$ polymorphism variants were evaluated using chi-square tests. The relationships between OPG rs3102735 T/C and rs $2073618 \mathrm{G} / \mathrm{C}$ genotypes and risk of RA were determined by computing ORs and $95 \% \mathrm{CI}$ using logistic regression analyses and by using crude ORs. The Hardy-Weinberg equilibrium (HWE) was tested by a goodness-of-fit chi-square test to compare the observed genotype frequencies with the expected frequencies among the controls. All analyses were performed using the SAS software (ver. 9.1.3; SAS Institute, Cary, NC, USA). Besides, stratified analyses between OPG rs3102735 T/C polymorphisms and the risk of rheumatoid arthritis were made depending on gender, age, CRP status, ACPA status, RF status, ESR, DAS28, and functional class.

\section{RESULTS}

\section{Characteristics of the study population}

Demographic and clinical characteristics of all patients are summarized in Table 1. Patients were adequately matched for age and gender $(\mathrm{P}=0.080$ and 0.962 , respectively). Ad- 
ditionally, the genotype distributions of OPG rs $3102735 \mathrm{~T} / \mathrm{C}$ and rs $2073618 \mathrm{G} / \mathrm{C}$ in all patients are illustrated in Table 2. The genotype frequencies observed for the polymorphisms in the controls were in HWE for OPG rs3102735 T/C $(\mathrm{P}=0.977)$ and rs2073618 G/C $(\mathrm{P}=0.913)$.

Table 1. Patient demographics and risk factors in rheumatoid arthritis, all subjects.

\begin{tabular}{lccc}
\hline Variable & Patients $(\mathrm{N}=574)$ & Controls $(\mathrm{N}=804)$ & $\mathrm{P}$ \\
\hline Age (years) & $54.46 \pm 15.11$ & $55.74 \pm 10.53$ & 0.080 \\
Female/male & $427 / 147$ & $599 / 205$ & -962 \\
Age at onset (years, mean $\pm \mathrm{SD})$ & $45.62 \pm 12.93$ & - & - \\
Disease duration (years, mean $\pm \mathrm{SD})$ & $8.88 \pm 9.16$ & - & - \\
Treatment duration (years, mean $\pm \mathrm{SD})$ & $7.59 \pm 7.79$ & - & - \\
RF-positive [N (\%)] & $456(79.44 \%)$ & - & - \\
ACPA positive [N (\%)] & $300(52.26 \%)$ & - & - \\
CRP-positive [N (\%)] & $323(56.27 \%)$ & - & - \\
ESR (mm/h) & $33.66 \pm 25.20$ & - & - \\
DAS28 & $4.29 \pm 1.47$ & - & - \\
Functional class [N (\%)] & $73(12.71 \%)$ & - & - \\
I & $256(44.60 \%)$ & - & - \\
II & $209(36.41 \%)$ & $36(6.27 \%)$ & - \\
III & $3 V$ & - & \\
IV & & - & \\
SD $=$ standard deviation; RF $=$ rheumatoid factor; ACPA $=$ anti-cyclic citrullinated peptide antibodies; CRP $=$ \\
C-reactive protein; ESR = erythrocyte sedimentation rate; DAS28 = RA disease activity score.
\end{tabular}

\section{Associations between OPG rs3102735 T/C and rs2073618 G/C polymorphisms and the risk of RA}

Logistic regression analyses showed that the OPG rs $3102735 \mathrm{~T} / \mathrm{C}$ and rs $2073618 \mathrm{G} / \mathrm{C}$ polymorphisms were not associated with the risk of RA (Table 2).

Table 2. Logistic regression analysis of associations between OPG rs3102735 T/C and rs 2073618 G/C polymorphisms and the risk of rheumatoid arthritis.

\begin{tabular}{|c|c|c|c|c|c|c|}
\hline \multirow[t]{2}{*}{ Genotype } & \multicolumn{2}{|c|}{ Patients* $(\mathrm{N}=574)$} & \multicolumn{2}{|c|}{ Controls $(\mathrm{N}=804)$} & \multirow[t]{2}{*}{ OR $(95 \% \mathrm{CI})$} & \multirow[t]{2}{*}{$\mathrm{P}$} \\
\hline & $\mathrm{N}$ & $\%$ & $\mathrm{~N}$ & $\%$ & & \\
\hline \multicolumn{7}{|c|}{ OPG rs3102735 T/C } \\
\hline TT & 418 & 73.1 & 546 & 69.3 & 1.00 & - \\
\hline $\mathrm{TC}$ & 142 & 24.8 & 220 & 27.9 & $0.84(0.66-1.08)$ & 0.175 \\
\hline $\mathrm{CC}$ & 12 & 2.1 & 22 & 2.8 & $0.71(0.35-1.46)$ & 0.353 \\
\hline $\mathrm{CC} v s \mathrm{TC} v s \mathrm{TT}$ & & & & & & 0.286 \\
\hline $\mathrm{TC}+\mathrm{CC}$ & 154 & 26.9 & 242 & 30.7 & $0.83(0.66-1.06)$ & 0.129 \\
\hline $\mathrm{TT}+\mathrm{TC}$ & 560 & 97.9 & 766 & 97.2 & 1.00 & - \\
\hline $\mathrm{CC}$ & 12 & 2.1 & 22 & 2.8 & $0.75(0.37-1.52)$ & 0.420 \\
\hline $\mathrm{C}$ allele & 166 & 14.5 & 264 & 16.8 & & \\
\hline \multicolumn{7}{|c|}{ OPG rs $2073618 \mathrm{G} / \mathrm{C}$} \\
\hline GG & 296 & 51.8 & 430 & 54.6 & 1.00 & - \\
\hline $\mathrm{GC}$ & 238 & 41.7 & 305 & 38.7 & $1.13(0.91-1.42)$ & 0.275 \\
\hline $\mathrm{CC}$ & 37 & 6.5 & 53 & 6.7 & $1.01(0.65-1.58)$ & 0.951 \\
\hline $\mathrm{CC} v s \mathrm{GC} v s \mathrm{GG}$ & & & & & & 0.542 \\
\hline $\mathrm{GC}+\mathrm{CC}$ & 275 & 48.2 & 358 & 45.4 & $1.12(0.90-1.39)$ & 0.320 \\
\hline $\mathrm{GG}+\mathrm{GC}$ & 534 & 93.5 & 735 & 93.3 & 1.00 & - \\
\hline $\mathrm{CC}$ & 37 & 6.5 & 53 & 6.7 & $0.96(0.62-1.48)$ & 0.858 \\
\hline $\mathrm{C}$ allele & 312 & 27.3 & 411 & 26.1 & & \\
\hline
\end{tabular}

*The genotyping was successful in 572 patients and 788 controls for $O P G \mathrm{rs} 3102735 \mathrm{~T} / \mathrm{C}$, and in 571 patients and 788 controls for $O P G$ rs $2073618 \mathrm{G} / \mathrm{C}$. OR = odds ratio; $\mathrm{CI}=$ confidence interval. 


\section{Stratification analyses of OPG rs3102735 T/C and rs2073618 G/C polymorphisms and the risk for $\mathrm{RA}$}

Stratification analyses were conducted according to age, gender, C-reactive protein status, anti-cyclic citrullinated peptide antibodies status, rheumatoid factor status, erythrocyte sedimentation rate, disease activity score 28 , and functional class (Tables 3 and 4). Older patients ( $\geq 55$ years) with the OPG rs3102735 TC and TC/CC genotypes showed a significantly lower risk of RA than patients with the TT genotype (TC vs TT: OR $=0.68,95 \% \mathrm{CI}=0.49-0.96, \mathrm{P}=0.029 ; \mathrm{TC}+\mathrm{CC} v s \mathrm{TT}: \mathrm{OR}=0.69,95 \% \mathrm{CI}=0.49-0.96, \mathrm{P}$ $=0.026$; Table 3). In dominant and heterozygote models, OPG rs2073618 GC and GC/CC genotypes were risk factors for RA among older patients (GC vs GG: OR $=1.53,95 \% \mathrm{CI}$ $=1.13-2.07, \mathrm{P}=0.006 ; \mathrm{GC}+\mathrm{CC}$ vs $\mathrm{GG}: \mathrm{OR}=1.43,95 \% \mathrm{CI}=1.07-1.92, \mathrm{P}=0.015$; Table 4). We also found a significantly increased risk of RA associated with the OPG rs2073618 $\mathrm{GC}$ and $\mathrm{GC} / \mathrm{CC}$ genotypes among functional class III+IV patients (GC vs GG: OR $=1.44$, $95 \% \mathrm{CI}=1.07-1.93, \mathrm{P}=0.018 ; \mathrm{GC}+\mathrm{CC} v s \mathrm{GG}: \mathrm{OR}=1.39,95 \% \mathrm{CI}=1.04-1.86, \mathrm{P}=0.024$; Table 4).

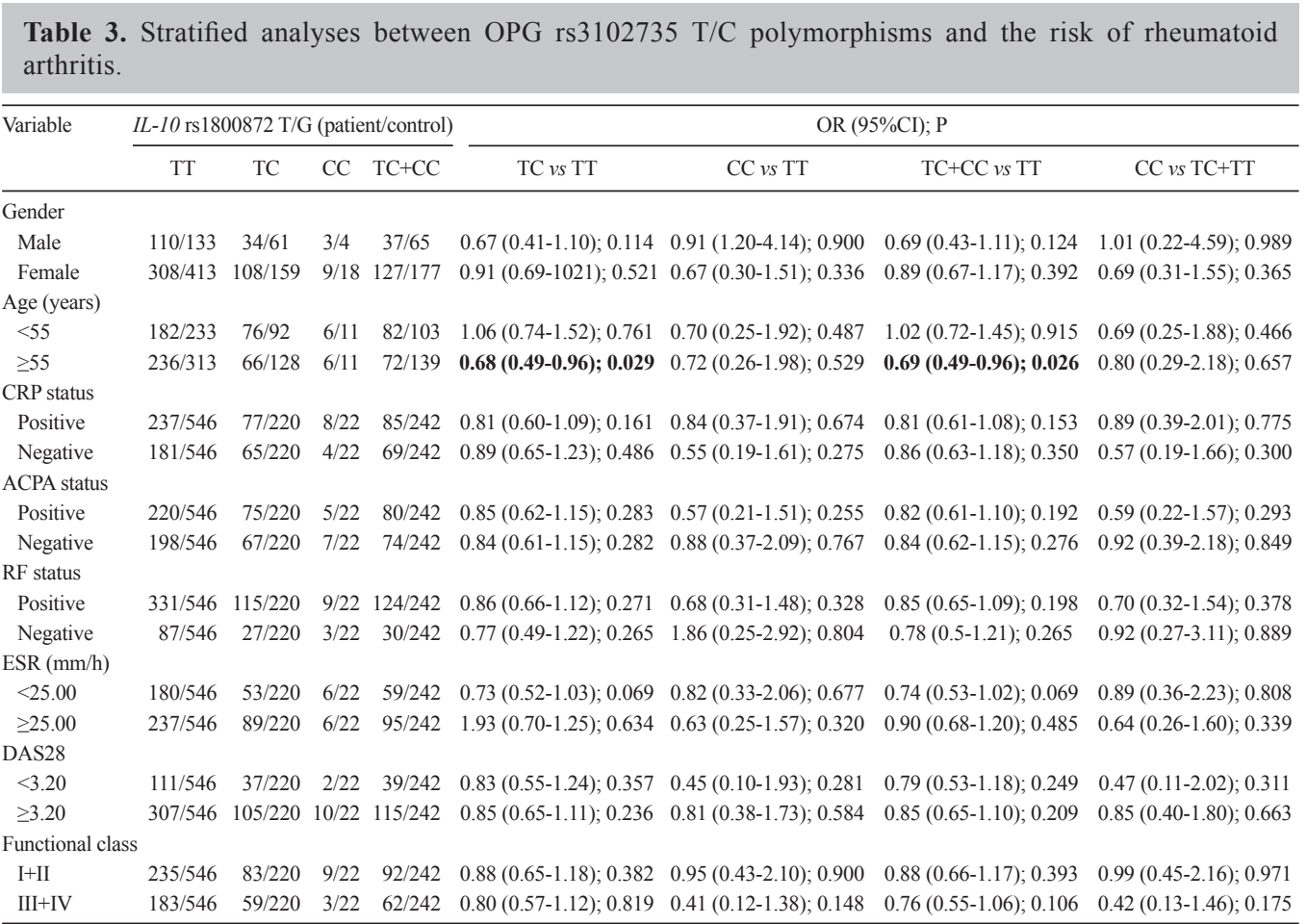

Bold values are statistically significant $(\mathrm{P}<0.05) . \mathrm{OR}=$ odds ratio; $\mathrm{CI}=$ confidence interval; $\mathrm{CRP}=\mathrm{C}$-reactive protein; $\mathrm{ACPA}=$ anti-cyclic citrullinated peptide antibodies, $\mathrm{RF}=$ rheumatoid factor; $\mathrm{ESR}=$ erythrocyte sedimentation rate; DAS28 $=$ RA disease activity score. 
Table 4. Stratified analyses between OPG rs2073618 G/C polymorphisms and the risk of rheumatoid arthritis.

\begin{tabular}{|c|c|c|c|c|c|c|c|c|}
\hline \multirow[t]{2}{*}{ Variable } & \multicolumn{4}{|c|}{ IL-10 rs $1800872 \mathrm{~T} / \mathrm{G}$ (patient/control) } & \multicolumn{4}{|c|}{ OR $(95 \% \mathrm{CI}) ; \mathrm{P}$} \\
\hline & GG & GC & $\mathrm{CC}$ & $\mathrm{GC}+\mathrm{CC}$ & GC $v s$ GG & $\mathrm{CC} v s \mathrm{GG}$ & $\mathrm{GC}+\mathrm{CC} v s \mathrm{GG}$ & $\mathrm{CC} v s \mathrm{GC}+\mathrm{GG}$ \\
\hline \multicolumn{9}{|l|}{ Gender } \\
\hline Male & $74 / 90$ & $63 / 92$ & $9 / 18$ & $72 / 110$ & $0.83(0.53-1.30) ; 0.420$ & $0.61(0.26-1.43) ; 0.256$ & $0.80(0.52-1.22) ; 0.296$ & $0.66(0.29-1.52) ; 0.334$ \\
\hline Female & $222 / 340$ & $175 / 213$ & $28 / 35$ & $203 / 248$ & $1.26(0.97-1.64) ; 0.086$ & $1.23(0.23-2.07) ; 0.448$ & $1.25(0.98-1.61) ; 0.078$ & $1.11(0.67-1.86) ; 0.679$ \\
\hline \multicolumn{9}{|l|}{ Age (years) } \\
\hline$<55$ & $150 / 174$ & $93 / 139$ & $21 / 22$ & $114 / 161$ & $0.78(0.55-1.39) ; 0.146$ & $1.11(0.59-2.09) ; 0.754$ & $0.82(0.59-1.14) ; 0.235$ & $1.23(0.66-2.29) ; 0.514$ \\
\hline$\geq 55$ & $146 / 256$ & $145 / 166$ & $16 / 31$ & $161 / 197$ & 1.53 (1.13-2.07); 0.006 & $0.91(0.48-1.71) ; 0.759$ & 1.43 (1.07-1.92); 0.015 & $0.75(0.40-1.39) ; 0.361$ \\
\hline \multicolumn{9}{|l|}{ CRP status } \\
\hline Positive & $171 / 430$ & $128 / 305$ & $23 / 53$ & $151 / 358$ & $1.06(0.80-1.39) ; 0.698$ & $1.09(0.65-1.84) ; 0.742$ & $1.06(0.82-1.38) ; 0.657$ & 1.07 (0.64-1.77); 0.803 \\
\hline Negative & $125 / 430$ & $110 / 305$ & $14 / 53$ & $124 / 358$ & $1.24(0.92-1.67) ; 0.152$ & $0.91(0.49-1.69) ; 0.763$ & $1.19(0.90-1.59) ; 0.229$ & $0.83(0.45-1.52) ; 0.538$ \\
\hline \multicolumn{9}{|l|}{ ACPA status } \\
\hline Positive & $149 / 430$ & $132 / 305$ & $19 / 53$ & $151 / 358$ & $1.25(0.95-1.65) ; 0.115$ & $1.04(0.59-1.80) ; 0.905$ & $1.23(0.93-1.59) ; 0.148$ & $0.94(0.55-1.61) ; 0.816$ \\
\hline Negative & $147 / 430$ & $106 / 305$ & $18 / 53$ & $124 / 358$ & $1.02(0.76-1.36) ; 0.911$ & $0.99(0.56-1.75) ; 0.982$ & $1.01(0.77-1.34) ; 0.926$ & $0.99(0.57-1.72) ; 0.962$ \\
\hline \multicolumn{9}{|l|}{ RF status } \\
\hline Positive & $241 / 430$ & $186 / 305$ & $27 / 53$ & $213 / 358$ & 1.09 (0.86-1.39); 0.493 & $0.91(0.56-1.48) ; 0.702$ & $1.06(0.84-1.34) ; 0.613$ & $0.88(0.54-1.42) ; 0.591$ \\
\hline Negative & $55 / 430$ & $52 / 305$ & $10 / 53$ & $62 / 358$ & $1.33(0.89-2.00) ; 0.166$ & $1.48(0.71-3.07) ; 0.298$ & $1.35(0.92-2.00) ; 0.127$ & $1.30(0.64-2.63) ; 0.471$ \\
\hline \multicolumn{9}{|l|}{$\operatorname{ESR}(\mathrm{mm} / \mathrm{h})$} \\
\hline$<25.00$ & $126 / 430$ & $95 / 305$ & $19 / 53$ & $114 / 358$ & $1.06(0.78-1.44) ; 0.694$ & $1.22(0.70-2.14) ; 0.481$ & 1.09 (0.81-1.45); 0.574 & $1.19(0.69-2.06) ; 0.527$ \\
\hline$\geq 25.00$ & $170 / 430$ & $133 / 305$ & $18 / 53$ & $151 / 358$ & $1.19(0.91-1.55) ; 0.210$ & $0.86(0.49-1.51) ; 0.597$ & $1.14(0.88-1.47) ; 0.326$ & $0.80(0.46-1.38) ; 0.421$ \\
\hline \multicolumn{9}{|l|}{ DAS28 } \\
\hline$<3.20$ & $75 / 430$ & $61 / 305$ & $13 / 53$ & $74 / 358$ & $1.15(0.79-1.66) ; 0.467$ & $1.41(0.73-2.71) ; 0.307$ & $1.19(0.84-1.68) ; 0.342$ & $1.33(0.70-2.50) ; 0.383$ \\
\hline$\geq 3.20$ & $221 / 430$ & $177 / 305$ & $24 / 53$ & $201 / 358$ & 1.13 (0.88-1.44); 0.334 & $0.88(0.53-1.47) ; 0.626$ & 1.09 (0.86-1.39); 0.465 & 0.84 (0.51-1.38); 0.481 \\
\hline \multicolumn{9}{|c|}{ Functional class } \\
\hline $\mathrm{I}+\mathrm{II}$ & $183 / 430$ & $123 / 305$ & $24 / 53$ & $147 / 358$ & 0.95 (0.73-1.24); 0.680 & $0.93(0.55-1.59) ; 0.793$ & $0.95(0.73-1.23) ; 0.670$ & $0.95(0.57-1.61) ; 0.854$ \\
\hline III+IV & $113 / 430$ & $115 / 305$ & $16 / 53$ & $131 / 358$ & 1.44 (1.07-1.93); 0.018 & $1.15(0.63-2.09) ; 0.689$ & 1.39 (1.04-1.86); 0.024 & 0.97 (0.55-1.74); 0.927 \\
\hline
\end{tabular}

\section{DISCUSSION}

In the present study, we evaluated the association between OPG gene polymorphisms (rs3102735 T/C and rs2073618 G/C) and patients with RA. Our results suggest that OPG rs $3102735 \mathrm{~T} / \mathrm{C}$ and rs $2073618 \mathrm{G} / \mathrm{C}$ polymorphisms are not related with the risk of RA. The results of the stratification analyses suggest the following: OPG rs3102735 TC and TC/CC genotypes may decrease the risk of RA among older patients in dominant and heterozygote models; OPG rs2073618 GC and GC/CC genotypes may increase the risk for RA among older patients in dominant and heterozygote models; and OPG rs2073618 GC and GC/CC genotypes may increase the risk of RA in functional class III+IV patients.

It is known that the RANKL/RANK/OPG system plays an important role in the pathogenesis of RA (Bar-Shavit, 2007; Furuya et al., 2007; Nakashima and Takayanagi, 2011). RANKL is expressed and released by osteoblasts and activated $\mathrm{T}$ lymphocytes (Kong et al., 1999) and promotes osteoclastic bone destruction. OPG protects against this bone destruction by preventing the binding of RANKL with its receptor, RANK; this is a key mechanism for controlling differentiation and bone destruction in RA (Haynes et al., 2001; Hikita and Tanaka, 2005). OPG is expressed in osteoblasts, chondrocytes, and bone marrow. Serum OPG is decreased in the synovium and serum of patientswith RA (Skoumal et al., 2005), and a low serum OPG/RANKL ratio is related to the progression of joint destruction in early RA (Geusens et al., 2006). 
Genetic factors have been shown to play a vital role in susceptibility and bone metabolism in RA (Kim et al., 2007; Hughes et al., 2010). Several SNPs in the RANKL gene and the OPG gene, which might influence the binding of transcription factors, have been reported to be significantly associated with bone metabolism and susceptibility to RA (Kim et al., 2007; Assmann et al., 2010). The OPG gene encodes a known regulator of bone remodeling and maintains a fine balance between bone formation and resorption, involving osteoblasts and osteoclasts, and thus potentially contributes to the pathophysiology of osteoporosis (Simonet et al., 1997). Polymorphisms in the OPG gene help determine the bone mineral density and the presence of osteoporosis in patients with RA (Styrkarsdottir et al., 2008). Thus, OPG gene polymorphisms are interesting candidates for analyzing the influence of susceptibility to RA and osteoporosis (Mencej-Bedrac et al., 2009).

Many studies have investigated the association between OPG polymorphisms and RA (Furuya et al., 2007; Assmann et al., 2010; Xu et al., 2014). Furuya et al. (2007) conducted the first study of the OPG SNP rs2073618 and found no significant correlation with RA severity in Japanese patients. Xu et al. (2014) showed no significant difference in the distribution frequency of the alleles and genotypes of OPG (rs2073618 and rs3102735) between the RA group and controls in a Chinese population. However, the RA group showed significantly higher serum levels of RANKL, a higher RANKL/OPG ratio, and a lower serum level of OPG than the controls in the study. A German article also reported that OPG rs3102735 T/C and rs2073618 G/C polymorphisms showed no significant difference between patients with RA and healthy controls in a Caucasian population (Assmann et al., 2010). Thus, it appears that OPG rs $3102735 \mathrm{~T} / \mathrm{C}$ and $\mathrm{rs} 2073618 \mathrm{G} / \mathrm{C}$ polymorphisms are not associated with the risk for RA in Asian or Caucasian populations, indicating that the correlation between the two SNPs and RA may not be associated with ethnicity. Our data showed that the OPG rs3102735 T/C and rs $2073618 \mathrm{G} / \mathrm{C}$ polymorphisms may not be associated with the risk of RA, which is consistent with the conclusions of the three aforementioned studies.

The highlight of our study was the discovery of some valuable results after the stratification analyses. In dominant and heterozygote models, the OPG rs $3102735 \mathrm{TC}$ and TC/CC genotypes may decrease the risk of RA among older patients, whereas the OPG rs2073618 $\mathrm{GC}$ and $\mathrm{GC} / \mathrm{CC}$ genotypes were risk factors for RA among older patients, indicating that the relationship between various SNPs in the OPG gene and risk of RA differed. When we conducted stratification analyses according to functional class, the results suggested that the OPG rs $2073618 \mathrm{GC}$ and $\mathrm{GC} / \mathrm{CC}$ genotypes increase the risk of RA in functional class III+IV patients, indicating that the severity of joint destruction in patients with RA may be associated with expression of the OPG gene.

Several limitations of the present study need to be addressed. First, this was a hospitalbased case-control study, hence, selection bias was unavoidable and the patients are not representative of the general population. Second, the polymorphisms we investigated, based on functional considerations, may not offer a comprehensive view of the genetic variability in OPG. Third, the sample size of this study was not large enough to evaluate low-penetrance effects of the SNPs. Finally, we did not investigate all aspects of association between SNPs of the OPG gene and bone and joint injury in patients with RA; for example, whether OPG gene polymorphisms influence bone destruction via altering serum OPG levels remains to be clarified.

In conclusion, the present study suggests that the OPG rs3102735 $\mathrm{TC}$ and $\mathrm{TC} / \mathrm{CC}$ genotypes may decrease the risk of RA among older patients, whereas the OPG rs2073618 GC and $\mathrm{GC} / \mathrm{CC}$ genotypes were risk factors for RA among older patients in dominant and hetero- 
zygote models. Furthermore, the OPG rs $2073618 \mathrm{GC}$ and GC/CC genotypes may increase the risk of RA in functional class III+IV patients, in comparison with the GG genotype. However, the results were obtained from one moderate-sized sample of Chinese Han patients. Larger sample sizes and well-designed studies with ethnically diverse populations to further evaluate the impact of OPG SNPs on RA susceptibility are warranted.

\section{Conflict of interest}

The authors declare no conflict of interest.

\section{ACKNOWLEDGMENTS}

Research supported in part by National Natural Science Foundation of China (\#81371927) and the Changzhou Foundation for Applied Basic Research (\#CJ20130027).

\section{REFERENCES}

Assmann G, Koenig J, Pfreundschuh M, Epplen JT, et al. (2010). Genetic variations in genes encoding RANK, RANKL, and OPG in rheumatoid arthritis: a case-control study. J. Rheumatol. 37: 900-904.

Bar-Shavit Z (2007). The osteoclast: a multinucleated, hematopoietic-origin, bone-resorbing osteoimmune cell. J. Cell Biochem. 102: 1130-1139.

Baud'huin M, Duplomb L, Ruiz Velasco C, Fortun Y, et al. (2007). Key roles of the OPG-RANK-RANKL system in bone oncology. Expert Rev. Anticancer Ther. 7: 221-232.

Boyce BF and Xing L (2008). Functions of RANKL/RANK/OPG in bone modeling and remodeling. Arch. Biochem. Biophys. 473: 139-146.

Cheng J, Zhang H, Zhuang C and Liu R (2012). Peptidylarginine deiminase type 4 and methyl-CpG binding domain 4 polymorphisms in Chinese patients with rheumatoid arthritis. J. Rheumatol. 39: 1159-1165.

Chu CQ, Field M, Allard S, Abney E, et al. (1992). Detection of cytokines at the cartilage/pannus junction in patients with rheumatoid arthritis: implications for the role of cytokines in cartilage destruction and repair. Br. J. Rheumatol. 31: 653-661.

Deleuran BW, Chu CQ, Field M, Brennan FM, et al. (1992). Localization of interleukin-1 alpha, type 1 interleukin-1 receptor and interleukin-1 receptor antagonist in the synovial membrane and cartilage/pannus junction in rheumatoid arthritis. Br. J. Rheumatol. 31: 801-809.

Furuya T, Hakoda M, Ichikawa N, Higami K, et al. (2007). Associations between HLA-DRB1, RANK, RANKL, OPG, and IL-17 genotypes and disease severity phenotypes in Japanese patients with early rheumatoid arthritis. Clin. Rheumatol. 26: 2137-2141.

Geusens PP, Landewe RB, Garnero P, Chen D, et al. (2006). The ratio of circulating osteoprotegerin to RANKL in early rheumatoid arthritis predicts later joint destruction. Arthritis Rheum. 54: 1772-1777.

Gravallese EM, Manning C, Tsay A, Naito A, et al. (2000). Synovial tissue in rheumatoid arthritis is a source of osteoclast differentiation factor. Arthritis Rheum. 43: 250-258.

Haynes DR, Crotti TN, Loric M, Bain GI, et al. (2001). Osteoprotegerin and receptor activator of nuclear factor kappaB ligand (RANKL) regulate osteoclast formation by cells in the human rheumatoid arthritic joint. Rheumatology 40: 623-630.

Hikita A and Tanaka S (2005). Involvement of osteoclasts in cartilage and bone destruction in rheumatoid arthritis. Nihon Rinsho. 63 (Suppl 1): 84-86.

Hofbauer LC and Heufelder AE (2001). Role of receptor activator of nuclear factor-kappaB ligand and osteoprotegerin in bone cell biology. J. Mol. Med. 79: 243-253.

Hughes LB, Reynolds RJ, Brown EE, Kelley JM, et al. (2010). Most common single-nucleotide polymorphisms associated with rheumatoid arthritis in persons of European ancestry confer risk of rheumatoid arthritis in African Americans. Arthritis Rheum. 62: 3547-3553.

Kalinina Ayuso V, Makhotkina N, van Tent-Hoeve M, de Groot-Mijnes JD, et al. (2014). Pathogenesis of juvenile idiopathic arthritis associated uveitis: the known and unknown. Surv. Ophthalmol. 59: 517-531. 
Kim JG, Kim JH, Kim JY, Ku SY, et al. (2007). Association between osteoprotegerin (OPG), receptor activator of nuclear factor-kappaB (RANK), and RANK ligand (RANKL) gene polymorphisms and circulating OPG, soluble RANKL levels, and bone mineral density in Korean postmenopausal women. Menopause 14: 913-918.

Knevel R, de Rooy DP, Saxne T, Lindqvist E, et al. (2014). A genetic variant in osteoprotegerin is associated with progression of joint destruction in rheumatoid arthritis. Arthritis Res. Ther. 16: R108.

Kondo T, Kitazawa R, Maeda S and Kitazawa S (2004). 1 alpha,25 dihydroxyvitamin D3 rapidly regulates the mouse osteoprotegerin gene through dual pathways. J. Bone Miner. Res. 19: 1411-1419.

Kong YY, Feige U, Sarosi I, Bolon B, et al. (1999). Activated T cells regulate bone loss and joint destruction in adjuvant arthritis through osteoprotegerin ligand. Nature 402: 304-309.

Mencej-Bedrac S, Prezelj J, Kocjan T, Teskac K, et al. (2009). The combinations of polymorphisms in vitamin D receptor, osteoprotegerin and tumour necrosis factor superfamily member 11 genes are associated with bone mineral density. J. Mol. Endocrinol. 42: 239-247.

Morinaga T, Nakagawa N, Yasuda H, Tsuda E, et al. (1998). Cloning and characterization of the gene encoding human osteoprotegerin/osteoclastogenesis-inhibitory factor. Eur. J. Biochem. 254: 685-691.

Nakashima T and Takayanagi H (2011). RANKL signal and osteoimmunology. Clin. Calcium 21: 1131-1140.

Silman AJ (1988). The 1987 revised American Rheumatism Association criteria for rheumatoid arthritis. Br. J. Rheumatol. 27: 341-343.

Simonet WS, Lacey DL, Dunstan CR, Kelley M, et al. (1997). Osteoprotegerin: a novel secreted protein involved in the regulation of bone density. Cell 89: 309-319.

Skoumal M, Kolarz G, Haberhauer G, Woloszczuk W, et al. (2005). Osteoprotegerin and the receptor activator of NFkappa B ligand in the serum and synovial fluid. A comparison of patients with longstanding rheumatoid arthritis and osteoarthritis. Rheumatol. Int. 26: 63-69.

Styrkarsdottir U, Halldorsson BV, Gretarsdottir S, Gudbjartsson DF, et al. (2008). Multiple genetic loci for bone mineral density and fractures. N. Engl. J. Med. 358: 2355-2365.

Takayanagi H, lizuka H, Juji T, Nakagawa T, et al. (2000). Involvement of receptor activator of nuclear factor kappaB ligand/osteoclast differentiation factor in osteoclastogenesis from synoviocytes in rheumatoid arthritis. Arthritis Rheum. 43: 259-269.

Wittrant Y, Theoleyre S, Chipoy C, Padrines M, et al. (2004). RANKL/RANK/OPG: new therapeutic targets in bone tumours and associated osteolysis. Biochim. Biophys. Acta 1704: 49-57.

Xu S, Ma XX, Hu LW, Peng LP, et al. (2014). Single nucleotide polymorphism of RANKL and OPG genes may play a role in bone and joint injury in rheumatoid arthritis. Clin. Exp. Rheumatol. 32: 697-704.

Yasuda H, Shima N, Nakagawa N, Yamaguchi K, et al. (1998). Osteoclast differentiation factor is a ligand for osteoprotegerin/osteoclastogenesis-inhibitory factor and is identical to TRANCE/RANKL. Proc. Natl. Acad. Sci. U. S. A. 95: 3597-3602.

Yoshida S, Ikari K, Furuya T, Toyama Y, et al. (2014). An osteoprotegerin gene polymorphism is associated with an increased risk of hip fracture in Japanese patients with rheumatoid arthritis: results from the IORRA Observational Cohort Study. PLoS One 9: e104587. 